The overall evaluation of the use of crossbred Chinese dams resulted in negative economic balance : the increase in sow productivity was not large enough to compensate for the poorer carcass merit of progeny. These results were discussed considering the present evolution in the system of carcass payment in France due to the use of grading machines.

\title{
Genetic relationships between fat androstenone level in males and development of male and female genital tract in the pig
}

\author{
P. SELLIER ${ }^{(1)}$, M. BONNEAU ${ }^{(2)}$, J. GRUAND ${ }^{(3)}$
}

Institut National de la Recherche Agronomique

(1) Station de Génétique quantitative et appliquée, 78350 Jouy-en-Josas.

(2) Station de Recherches Porcines, Saint-Gilles, 35590 L'Hermitage.

(3) Station Expérimentale de Sélection Porcine, 86480 Rouillé.

A one-generation selection experiment was performed in order to assess the extent to which it is possible to select for reduced fat androstenone level (A) in boars while maintaining normal sexual maturity in boars and gilts. In Large White boars of around $114 \mathrm{~kg}$ liveweight. A was determined on a biopsy of fat, and testes size (TS) was estimated from live measurements of testes width and scrotal area. Three groups of sires (4 per group) were kept for breeding by A.I. : 1) group $S$ showing low $A$ (intensity of selection $i=-1.50$ unit of phenotypic standard deviation) and small TS $(i=-2.74)$, 2) group $L$ with low $A(i=-1.32)$ and large TS $(i=+.50)$, and 3) group C ("control »). Records for A and TS at $104 \mathrm{~kg}$ and for A and genital tract development at slaughter $(124 \mathrm{~kg})$ were collected on 236 male offspring from these boars. Percentage of puberal gilts and genital tract development at slaughter $(124 \mathrm{~kg})$ were recorded on 187 female offspring. A highly significant response to selection "against " A was observed in both group $S$ and $\mathrm{L}$. A result of particular interest is that a normal development of testes and Cowper's glands was preserved in the sons from $\mathrm{L}$ sires, at least at $124 \mathrm{~kg}$, though they exhibited a large decrease in $\mathrm{A}$ at the usual slaughter weight $(104 \mathrm{~kg})$. However, a highly significant delay in puberty was found in gilts from both groups S and L : only 35-37\% of those gilts reached puberty at $124 \mathrm{~kg}$, as compared to $79 \%$ in the "control " group. Estimates of realized genetic parameters for A and TS were derived from the coefficients of 2-trait indexes in retrospect and selection responses in the groups $\mathrm{S}$ and $\mathrm{L}$. Realized heritability estimates are $.89 \pm .39$ and $.48 \pm .24$ for $\mathrm{A}$ and TS, respectively. The genetic correlation between A and TS was found to be positive (around .55) showing that decreasing androstenone content in fat and increasing testes size are genetically antagonistic.

\section{Note on the age and replacement policy of boars in the French breeding herds}

\author{
D. LALOE ${ }^{(1)}$, L. OLLIVIER (2)
}

(1) U.P.R.A. Porcine, 95 bis, boulevard Péreire, 75017 Paris.

(2) INRA, Station de Génétique quantitative et appliquée, 78350 Jouy-en-Josas.

An analysis is presented of 37,339 matings declared by the French pedigree breeders (breeding companies excluded) over the period July 1st 1985-June 30th 1986. In those matings, 11,5 percent of which are artificial (A.I.), $62 \%$ are by boars selected on performance-test, either on-farm (CF) or in station (CI). The results show that the French breeders are now aware of the need for a quick renewal of their boars. The age at mating of these boars is indeed 15.6 months on average, which is 7 months below the figure of 15 years ago, and 5.4 months below the present situation for commercial boars. Replacement is particularly fast for CF boars, 13 month-old on average. The favourable consequences of this policy, in terms of genetic gain and dissemination of genetic 